\title{
The assessment of quantitative risk to road users from debris flow
}

\author{
M. G. Winter ${ }^{1,2^{*}}$ (D) and J. C. F. Wong ${ }^{3}$
}

\begin{abstract}
Background: A methodology for the quantitative risk assessment (QRA) of the impact of debris flow in a road environment has been developed and applied to two sites that are typically subject to high frequency-low magnitude and low frequency-high magnitude events. The methodology considers the probability of an event of a typical size, and the conditional probabilities of a vehicle being affected, given an event, and of damage (fatality) occurring given that the vehicle is affected. Scenarios covering a vehicle being hit by a debris flow and of a vehicle hitting a debris flow are considered. The computed Personal Individual Risk (PIR) is used to calculate worst case fatality probabilities for commuters and logistics truck drivers. The overall risk to society is expressed both by the annual probability of fatality amongst all road users, the Potential Loss of Life (PLL), and using the F-N diagram and is used to demonstrate the effect of a programme of management and mitigation works on the societal risk at one of the sites. The authors believe that this is the first full, formal quantitative risk assessment for debris flow risk to road users.

Results: The PIR for a single trip through the sites ranges between 1.147E-10 for the low frequency-high magnitude site and 1.583E-09 for the high frequency-low magnitude site. These figures increase to $1.248 \mathrm{E}-07$ and $1.922 \mathrm{E}-06$, respectively, when more frequent travellers are considered. The PLL for the two sites ranges between 2.616E-04 for the low frequency-high magnitude site and 4.083E-03 for the high frequency-low magnitude site. The F-N diagrams illustrate the Broadly Acceptable level of risk at the low frequency-high magnitude site and the partially Unacceptable level of risk at the high frequency-low magnitude site. The risk at the high frequency-low magnitude site is reduced to ALARP levels when management and mitigation measures extant as of October 2014 are considered.

Conclusions: The QRA proves an effective technique for understanding, comparing and articulating the differences in levels of risk and the temporal changes in risk at a given site as a result of landslide risk reduction activities.
\end{abstract}

Keywords: Landslides, Debris flow, Quantitative, Risk, Assessment

\section{Introduction}

The Scottish Road Network Landslides Study (Winter et al. 2005, 2006, 2009) evaluated the hazards and risks associated with landslides at a regional/national (panScotland) scale and identified sites most at risk, within a qualitative/semi-quantitative framework.

Typically, although not exclusively, as assessments move from small-scale (e.g. global or continental) to mediumscale (e.g. national or regional) to large-scale (e.g. site or

\footnotetext{
* Correspondence: mwinter@winterassociates.co.uk

${ }^{1}$ Formerly Transport Research Laboratory (TRL), Edinburgh now Winter Associates, Kirknewton, Midlothian, UK

${ }^{2}$ University of Portsmouth, Portsmouth, UK

Full list of author information is available at the end of the article
}

area) then the availability of quantitative information increases, and more detailed assessments are possible. Thus, while small- to medium-scale assessments may typically be conducted in a semi-quantitative framework, largescale assessments are more typically conducted quantitatively. In addition, it should be noted that even when regional quantitative risk assessments are undertaken (e.g. Redshaw et al. 2017) the nature and resolution of the data is such that the conclusions that can be drawn from the results will still be reflective of the regional nature of the assessment rather than of a quantitative assessment carried out at a larger scale with higher resolution data (Winter 2019). 
In contrast with qualitative risk analysis, which yields results in terms of weighted indices, relative ranks (e.g. low, moderate and high) or numerical classification, Quantitative Risk Assessment (QRA) quantifies the probability of a given level of loss and the associated uncertainties (Corominas et al. 2014).

Thus, while the qualitative risk assessment allowed the effective targeting of funds for management and mitigation activities, QRA at the highest risk sites is intended to provide greater focus on the risks and consequent management and mitigation actions. Most importantly, the use of quantitative techniques allows for the direct comparison of landslide fatality risks with other risks pertinent to the road network, including those relevant to other geohazards (e.g. floods) and more commonly recognised risks that face society including the fatality risk from road traffic collisions (Winter 2019). Similarly, because QRA is an objective and, in principle, repeatable process, comparisons can be made from one location (site, region, etc.) to another (Corominas et al. 2014) and costbenefit analyses can be performed to prioritise investments between risk reduction activities for different hazards (e.g. landslide, flood, road traffic collision) (Winter 2019).

This paper outlines the methodology developed to undertake the QRA for rapid debris flow (Winter 2020) risk for users. The outcomes are set within the framework of the As Low As Reasonably Practicable (ALARP) approach which allows comparison with the levels of risk that the Health and Safety Executive deems acceptable in the nuclear industry (Anon. 1992; HSE 2001), for example.

The outcomes will allow a greater degree of confidence in decisions on the allocation of budgets for landslide risk reduction (Winter 2014) as well as giving a sound basis to such actions (and inactions). The outcomes also will be valuable in the light of potential future landslide incidents and any associated injuries. There is also a strong link with work on economic impact assessment of landslides (Winter et al. 2014a, 2018) as this work will help to better define the relations between the frequency and magnitude of landslide events, albeit only for those of magnitudes that are extant, and suggest a likely temporal framework for repeated events.

The consequences of an event of a given magnitude were considered in terms of disruption or damage to the carriageway, and the vulnerability of road users determined in order to allow estimates of the annual probability of a fatality as a result of debris flow in the study area. The methodology has been demonstrated using the A83 Rest and be Thankful (Wong and Winter 2018) and A85 Glen Ogle (Winter 2018) sites.

\section{Sites}

Two study sites were selected to represent a range of conditions with the A83 representing a site of frequent debris flow events of relatively small magnitude and the A85 (Fig. 1) representing sites of relatively low (but to an extent unknown) frequency but higher magnitude.

Both sites have a well-documented recent history of debris flow activity (Winter et al. 2005, 2006, 2009, 2013a, 2019) and were amongst the highest risk sites identified in the Scottish Road Network Landslides Study (Winter et al. 2005, 2009).

A desk study of the landslide hazards, and the setting of the road in both the context of the road network and of the regional geology was undertaken for each site.

\section{A83 Rest and be Thankful}

The A83 trunk (strategic or national) road is a $157 \mathrm{~km}$ long single two-lane carriageway connecting the A82 trunk road at Tarbet on Loch Lomond south-westwards to Campbeltown in Kintyre, connecting principal towns such as Inveraray, Lochgilphead, Tarbert and Campbeltown as well as other areas such as Dunoon and Cowal, Kintyre, and the islands of Islay, Jura and Gigha with the Scottish trunk (strategic) road network. The status of the $51 \mathrm{~km}$ between Kennacraig and Campbeltown was upgraded from a local road to a trunk road on 4 August 2014. The A83 supports the economic activities in the region including agriculture, forestry and fisheries, energy production, transport and storage, tourism and public administration.

The section of the A83 trunk road between Ardgartan and the Rest and be Thankful through Glen Croe is approximately $7 \mathrm{~km}$ long, starting from Ardgartan Village on Loch Long in the south-east towards the Rest and be Thankful car park in the north-west, near the junction with the B828. From Ardgartan the A83 (at $2 \mathrm{~m}$ AOD) runs above and predominantly to the east of Croe Water, with only a small section of about $300 \mathrm{~m}$ to the west, at the bottom of Glen Croe for about $3.3 \mathrm{~km}$ to the junction with the Old Military Road at about $90 \mathrm{~m}$ AOD. After this junction, the Old Military Road runs along the lower parts of the valley floor, while the A83 rises consistently at about $5^{\circ}$ (around 1 in 11) towards the Rest and be Thankful car park at about $260 \mathrm{~m}$ AOD.

Croe Water rises in the catchments to the south-west of Bealach a'Mhaim taking runoff from Beinn Luibhean (summit 858 m AOD), Beinn Ime (1011 m), Beinn Narnain $(926 \mathrm{~m})$ and The Cobbler (Ben Arthur) $(884 \mathrm{~m})$. It intersects the A83 at approximately $180 \mathrm{~m}$ AOD and 2 $\mathrm{km}$ south-east of the Rest and be Thankful car park. The stream in Glen Croe to the north of that point is a tributary of Croe Water which rises in High Glencroe to the south of the Rest and be Thankful car park. The road between Croe Water and the Rest and be Thankful car 


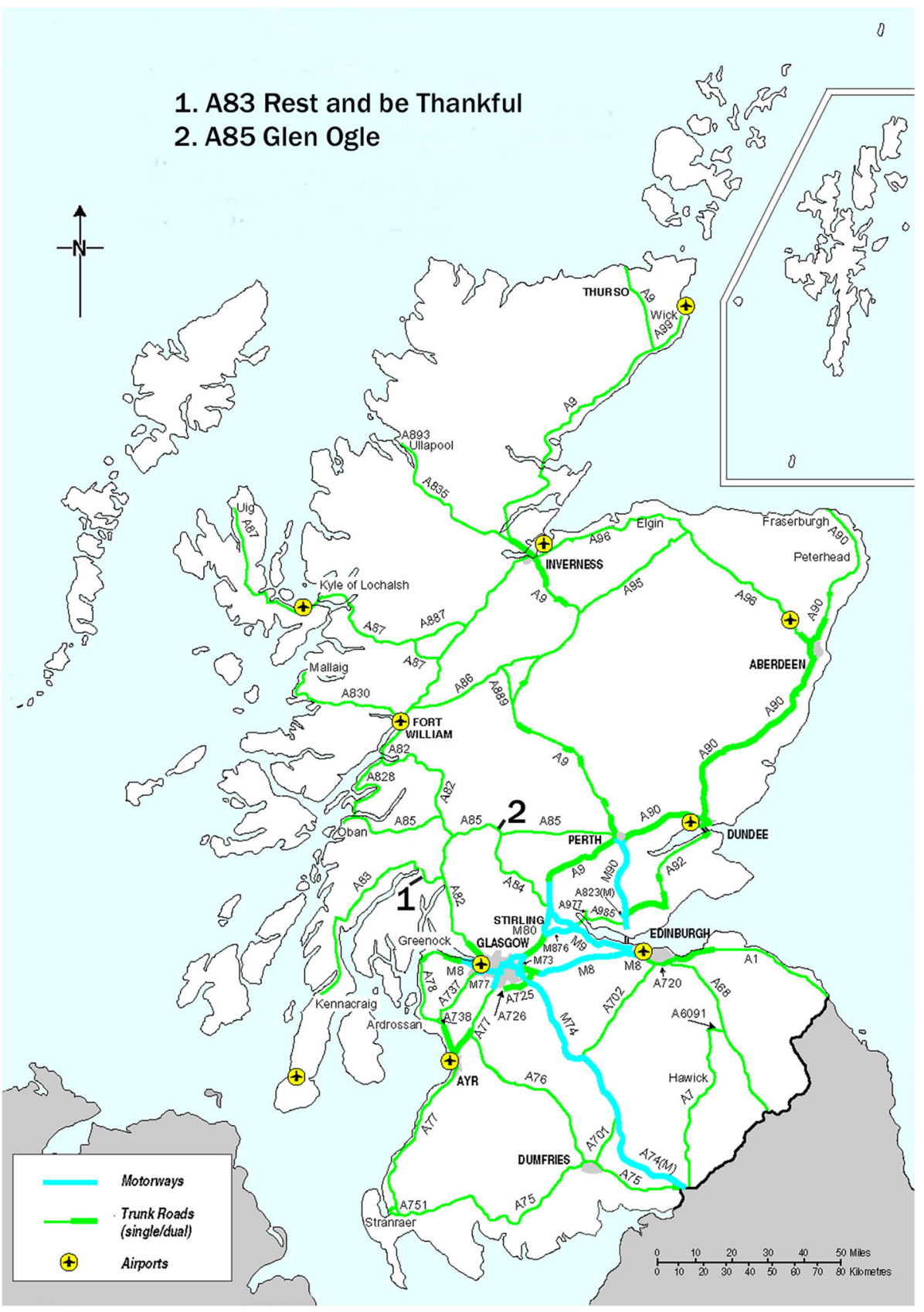

Fig. 1 Map of Scotland showing the two sites (1) A83 Rest and be Thankful; (2) A85 Glen Ogle

park is overlooked by Beinn Luibhean whereas that between Ardgartan and Croe Water is overlooked by The Cobbler (Ben Arthur).

The A83 Rest and be Thankful site, while not affected in August 2004, has been extremely active in recent years with multiple debris flow events and associated closures; events in 2007 (Fig. 2), 2008, 2009, 2011, 2012, 2014, 2015, 2017 and 2018 had an adverse effect on the travelling public. This has meant that the area has become the focus of not only concern but also of extensive landslide management and mitigation activity. This culminated in a study being commissioned to assess and make recommendations on potential landslide remediation actions (Anon. 2013; Winter and Corby 2012) and the active part of the site is identified in Fig. 3.

The primary landslide hazards at the site were identified within a GIS framework and Fig. 4 shows probable recent and relict landslide scars along with known source locations as illustrated. Typically, debris flow at the site initiates on the hillside and rapidly enters stream 


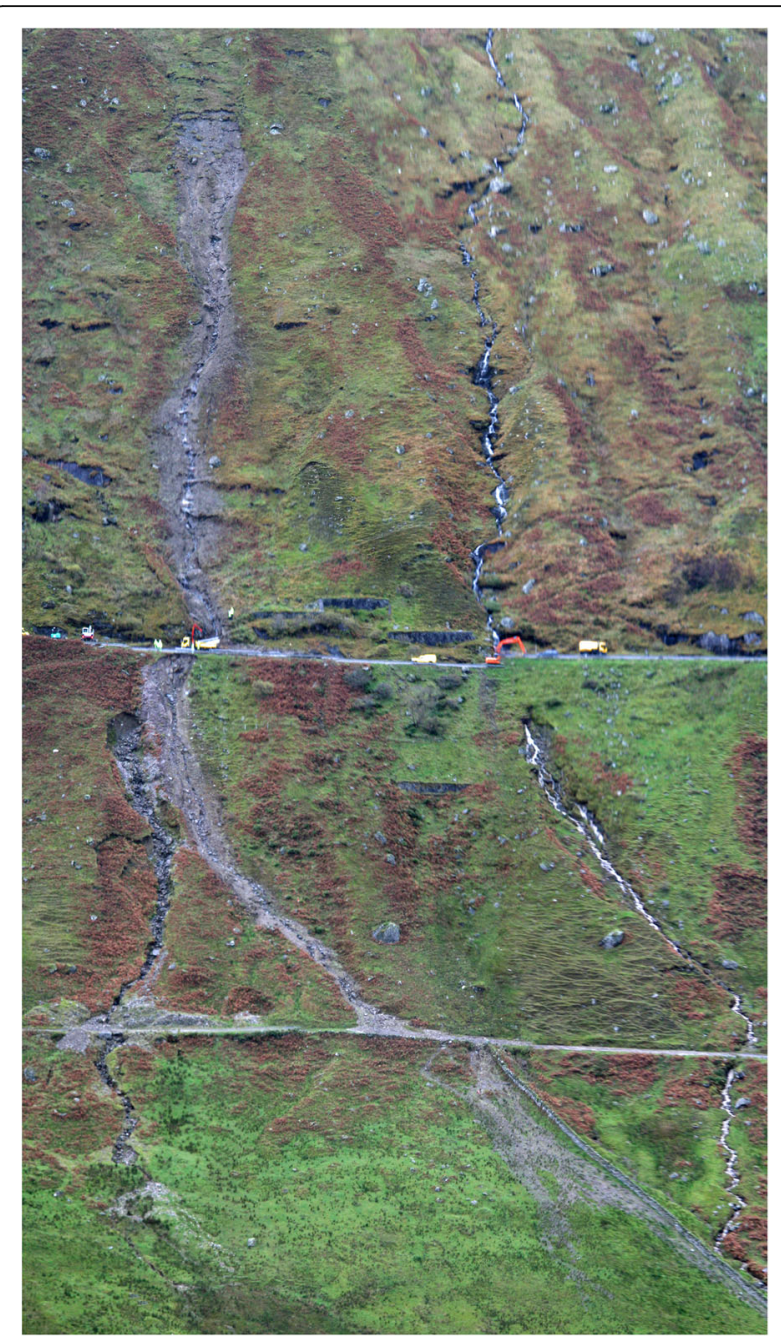

Fig. 2 View of the debris flows above and below the A83 on the approach to the Rest and be Thankful. The head scar is at approximately $370 \mathrm{~m}$ Above Ordnance Datum (AOD), the A83 at $240 \mathrm{~m} \mathrm{AOD}$ and the Old Military Road (OMR) at $180 \mathrm{~m} \mathrm{AOD}$

channels enabling the focus of the study hazard element of the study to be on the identification of stream channels (Fig. 5). These were measured in the GIS platform and then remeasured during a walkover to selectively ground truth the existence or otherwise of landslide scars identified in Fig. 4.

The review and site work was used to inform the work undertaken to establish the size and frequency of landslide slide hazards at the site for $\mathrm{P}($ Event $)$ while the stream channels dimensions were used to help determine $\mathrm{P}($ Wrong Place $)$ as part of the calculation of $\mathrm{P}($ Hit $\mid$ Event $)$.

\section{A85 Glen Ogle}

The A85 trunk road is a $139 \mathrm{~km}$-long single two-lane carriageway that connects the A9 at Perth in the east of Scotland with Oban in the west. A short stretch of non-trunk A85 connects the A9 with the A912 in the centre of Perth and it connects with the A816 (nontrunk) at Oban. The A85 supports the economic activities in the region including agriculture, forestry and fisheries, energy production, transport and storage, tourism, and public administration. (A short stretch of around $6.5 \mathrm{~km}$ of non-trunk A85 connects the A90 at Dundee with the A991 in the city centre via the airport and the railway station.)

The section of the A85 trunk road through Glen Ogle is a relatively narrow single-carriageway and climbs northwestward from Lochearnhead at around $100 \mathrm{~m}$ AOD. From Lochearnhead, the A85 runs to the west of Ogle Burn, which runs in the base of Glen Ogle, until the road crosses to the east flank of the glen after approximately $1.25 \mathrm{~km}$ (150 m AOD). From here the road runs above and to the east of Ogle Burn until the road levels out after around $5 \mathrm{~km}$. Here Ogle Burn becomes less significant and the road passes over it at around $300 \mathrm{~m}$ AOD. Ogle Burn rises in the hills just to the east of the road at approximately $363 \mathrm{~m}$ AOD. The road continues on the relatively flat ground that forms the pass between Glen Ogle and the valley to the north that in turn feeds into Glen Dochart and the road passes to the east of Lochan Lairig Cheile which drains to the north.

The events that closed the A85 in Glen Ogle in August 2004 are located towards the mid-point of this section approximately $1.7 \mathrm{~km}$ and $2.2 \mathrm{~km}$ from the southern end of the section.

Debris flow events at the A85 Glen Ogle were amongst the most notable events that occurred in August 2004 and led to the Scottish Road Network Landslides Study (Fig. 6). Other notable events occurred at the A83 between Glen Kinglas and to the north of Cairndow (9 August), and at the A9 to the north of Dunkeld (11 August). While there were no major injuries, the most dramatic events occurred at the A85 Glen Ogle, where 57 people had to be airlifted to safety when they became trapped between two major debris flows. The active part of the site is identified in Fig. 7).

As a point of interest, the part of the former Callander to Oban railway runs along the west flank of the slopes of Glen Ogle - this line was closed in 1965 but now provides a series of excellent viewpoints for the eastern flanks of Glen Ogle. An old military road, dating from the 1700s (eighteenth century), also runs through the glen (Fig. 8). Figure 8 also illustrates the key components of the August 2004 events at Glen Ogle. Figure 9 identifies both the August 2004 debris flows and other evidence of debris flow using information from Winter et al. (2006) and Milne et al. (2009, 2010). As is the case for the A83 site it is clear that the debris flow events on the hillside above the A85 are largely coincident with stream channels and as part of the hazard ground- 


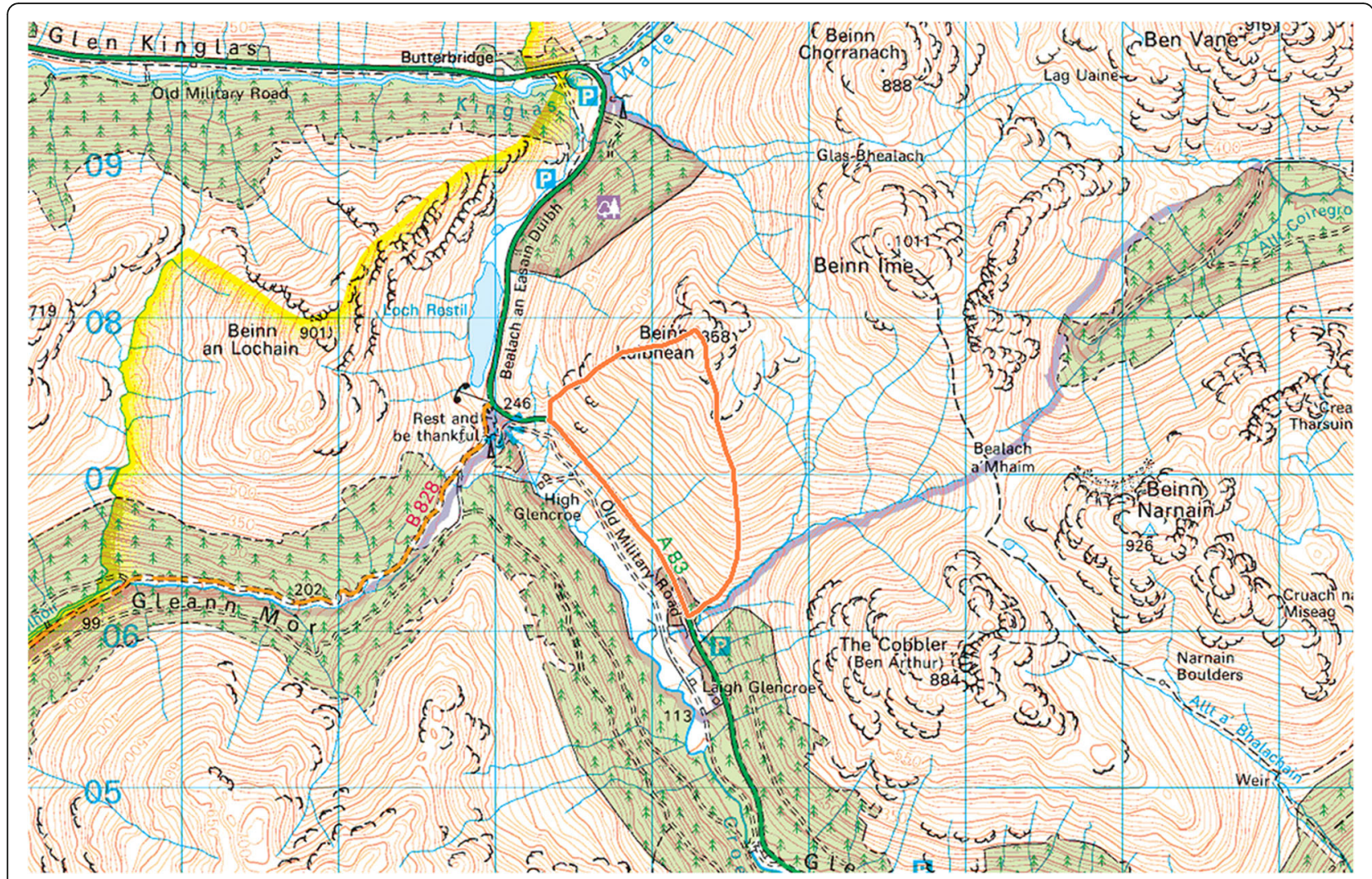

Fig. 3 Location plan of the A83 Rest and be Thankful study area outlined in red (Ordnance Survey 1:50,000, not to scale). Reproduced by permission of Ordnance Survey, on behalf of HMSO, $\odot$ Crown copyright and database rights, 2020. All rights reserved. Ordnance Survey Licence number 100046668

truthing, initial GIS-based estimates of the number and width of stream channels were measured on the ground to aid in the calculation of $\mathrm{P}($ Hit $\mid$ Event $)$.

\section{Methodology}

The methodology for the risk analysis was broadly based on that presented by Lee and Jones (2014) and adapted and expanded as the scenarios under consideration dictated. Accordingly, a definition for risk analysis was taken as follows:

$$
\begin{aligned}
\text { Risk }= & P(\text { Event }) \times P(\text { Hit } \mid \text { Event }) \\
& \times P(\text { Damage } \mid \text { Hit }) \times C
\end{aligned}
$$

where $\mathrm{P}($ Event $)$ is a measure of the expected likelihood of a landslide event per annum, $\mathrm{P}($ Hit $\mid$ Event $)$ is the annual probability of a vehicle 'hit' given that a landslide event occurs which involves both spatial and temporal probabilities of affecting the elements at risk, $\mathrm{P}($ Damage $\mid$ Hit $)$ is the annual probability of damage given that a 'hit' has occurred, as a measure of chance between 0 and 1 , and $C$ is the consequences as a result of the landslide event.

For the purposes of this work 'Damage' was taken to represent the fatality of one or more road users and effectively encompasses the concepts of both 'Damage' and 'Consequences' and Eq. (1) becomes:

$$
\begin{aligned}
\text { Risk }= & P(\text { Event }) \times P(\text { Hit } \mid \text { Event }) \\
& \times P(\text { Fatality } \mid \text { Hit })
\end{aligned}
$$

Two scenarios were considered, that of a vehicle being hit by a debris flow that reaches the road (A) and that of a vehicle hitting a debris flow that has already reached the road (B). At these two sites, and in normal operational circumstances, the only major exposure is that related to moving vehicles and road users. There are, for example, no formal opportunities for stopping or parking within either of the sites that could create risk to static elements at risk. As a result these two scenarios are the only possibilities of fatality amongst road users that may be logically deduced.

\section{$\mathrm{P}$ (Event)}

The relatively short timeframe over which an event inventory is available and the uncertainties surrounding the timings of past events, especially at the lower frequency site, were the most significant challenges of the work. As with many elements of QRA experienced 


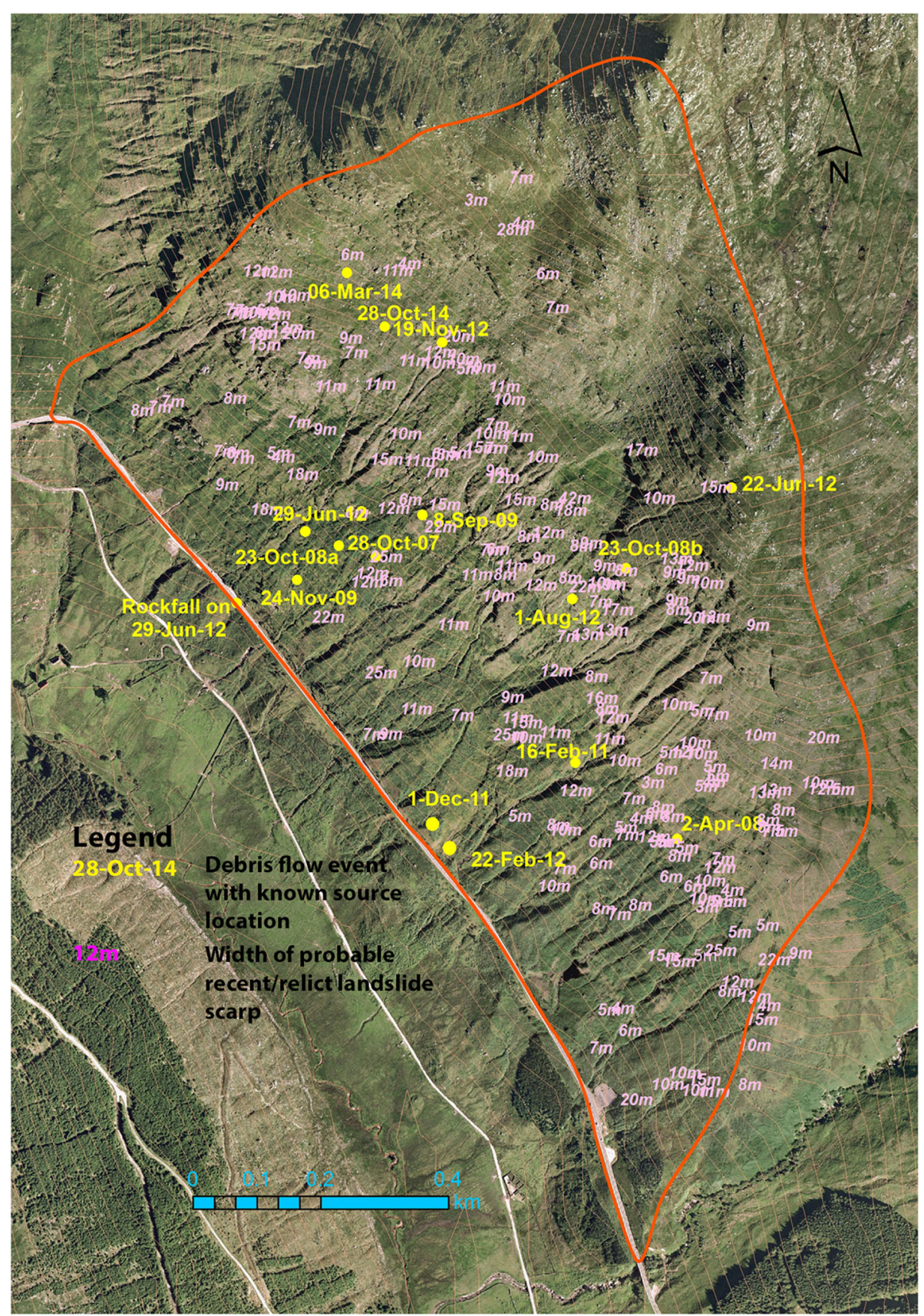

Fig. 4 Locations of probable recent and relict landslide scars at the A83 Rest and be Thankful. Base aerial photography reproduced by permission of Ordnance Survey, on behalf of HMSO, (c Crown copyright and database rights, 2020. All rights reserved. Ordnance Survey Licence number 100046668

engineering and geological judgement were combined with extensive knowledge of the sites and both published and unpublished information to develop frequencies that were considered to be representative of events of the typical known magnitude range of events at the sites (Winter et al. 2005, 2006, 2009, 2013a, 2014b; Wilson 2006; Milne 2008; Milne et al.
2009, 2010). Further relevant information on the A83 site, post-dating this study, is additionally available from McMillan and Holt (2019).

The magnitudes were based on the events that occured at the A83 between January 2003 and October 2014, while those for the A85 were based on the August 2004 events. While a total of 19 events at the A83 site 


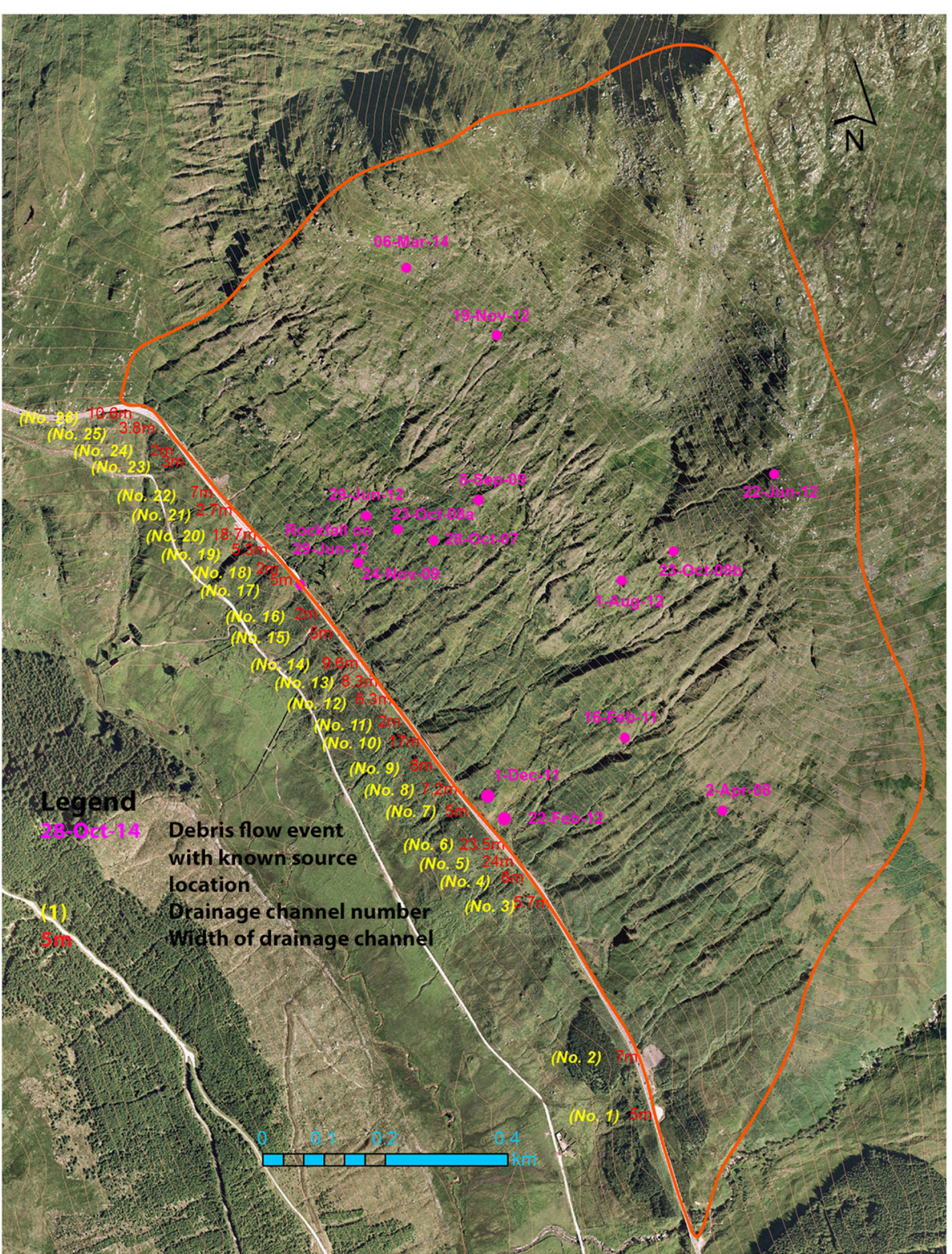

Fig. 5 Locations of the drainage channels at the A83 Rest and be Thankful as confirmed by field reconnaissance. Base aerial photography reproduced by permission of Ordnance Survey, on behalf of HMSO,๑ Crown copyright and database rights, 2020. All rights reserved. Ordnance Survey Licence number 100046668

gave a relatively robust estimate of frequency, albeit over a short time period, determining the frequency of events at the A85 was somewhat less certain. Milne (2008) reported that Wilson (2006) identified landslide scars on aerial photographs from the 1940s and 1950s that are no longer clearly discernible in the field or on more recent aerial photograph. This allowed the next most recent events to be taken to be sometime between 1940 and 1959 (a gap of between 45 to 64 years to 2004).

The resulting frequencies and magnitudes were determined as follows:
- A83: 0.83 events per annum of a magnitude of between $10 \mathrm{~m}^{3}$ and $1000 \mathrm{~m}^{3}$.

- A85: between 0.03125 and 0.04444 events per annum of a magnitude of between $3000 \mathrm{~m}^{3}$ and $10,000 \mathrm{~m}^{3}$, with the higher frequency taken forward for analysis.

\section{$\mathrm{P}$ (Hit|Event)}

When a debris flow occurs on the slopes above the road in the study area, the potential elements at risk are the moving vehicles using the road and the 


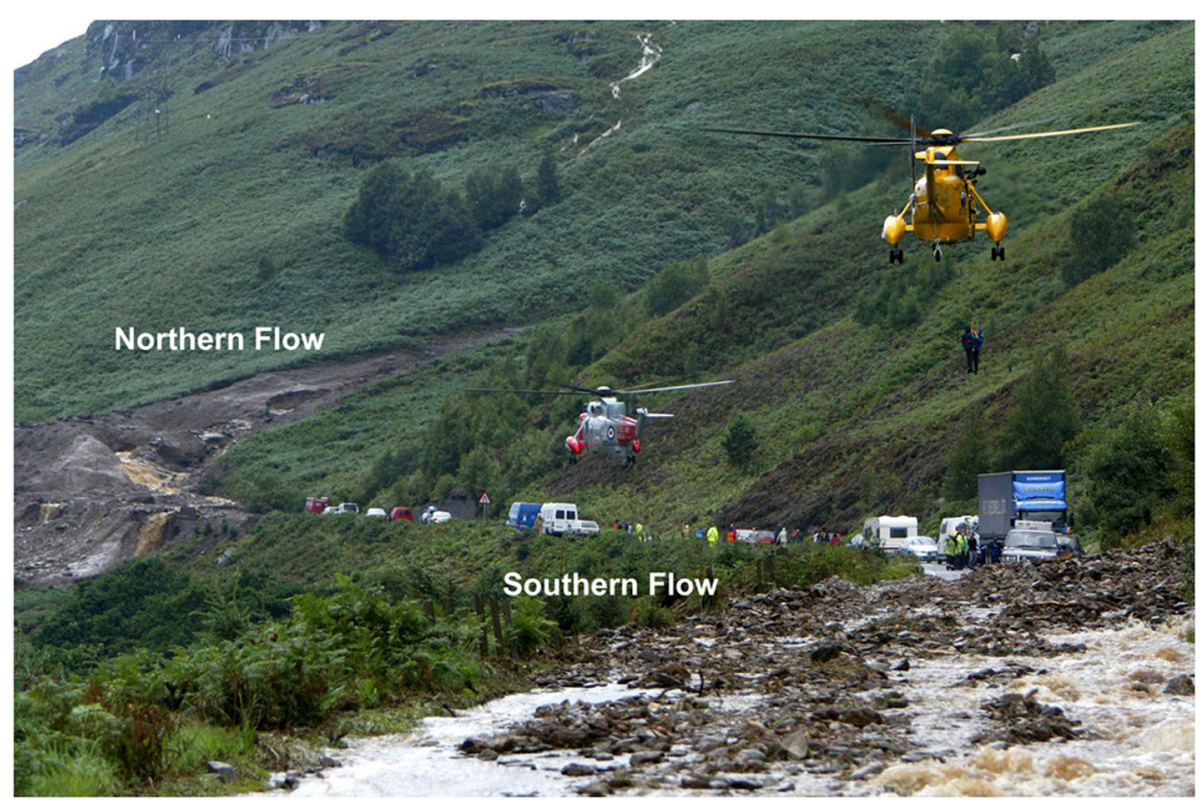

Fig. 6 Fifty-seven occupants of the 20 vehicles that were trapped between the two debris flows at the A85 in Glen Ogle were airlifted to safety. (๔) Perthshire Picture Agency: www.ppapix.co.uk)

associated road users (i.e. the drivers and passengers). $\mathrm{P}($ Hit $\mid$ Event $)$ is the conditional probability of a 'hit' on a non-stationary object per year given the occurrence of an event; it is the product of two components, namely $\mathrm{P}$ (Wrong Place) and $\mathrm{P}($ Wrong Time) (Lee and Jones 2014). P(Wrong Place) quantifies the spatial probability of a vehicle exposed to a hazard on a single trip in a year, while $\mathrm{P}$ (Wrong Time) indicates the temporal probability associated with the vehicle passing through the 'Wrong Place' on that trip. The product of $\mathrm{P}$ (Wrong Place) and $\mathrm{P}$ (Wrong Time) gives rise to $P($ Hit $\mid$ Event $)$, quantifying the probability of a 'hit' associated with a debris flow event or the probability of a vehicle being in the wrong place at the wrong time.

Discrete equations were developed for $\mathrm{P}$ (Wrong Place $)$ for Scenarios A and B while that for $\mathrm{P}$ (Wrong Time) is independent of the scenario considered. These equations consider hazard parameters such as the number and average width of potential debris flow channels; road and traffic parameters such as the width of the carriageway, annual traffic volumes and the mix of different types of vehicles; and vehicle parameters such as length, speed and the associated stopping distances. In some cases these parameters were combined to obtain, for example, metrics such as the weighted vehicle length for the mix of vehicles.

The scenarios for $\mathrm{P}$ (Wrong Place) for Scenarios A and $\mathrm{B}$ are illustrated in Figs. 10 and 11, respectively. The equation for Scenario A is as follows:

$$
P\left(\text { Wrong } \text { Place }_{A}\right)=\frac{L_{v}}{N_{H}\left(L_{s}+2\left(0.5 \times W_{C} / \tan 45^{\circ}\right)+2 L_{v}\right)}
$$

where $N_{H}$ is the number of stream channels (26 for A83; 21 for A85), $L_{s}$ is the average width of the stream channels $\left(7.83 \mathrm{~m}\right.$ for A83; $12.0 \mathrm{~m}$ for A85), and $W_{C}$ is the width of the carriageway ( $6.8 \mathrm{~m}$ from Anon. 2013 for A83 and observed for A85).

For Scenario B the equation is:

$$
P\left(\text { Wrong } \text { Place }_{B}\right)=\frac{L_{v}}{N_{H} \cdot D_{S}}
$$

where $N_{H}$ is defined for Eq. (3) above, $L_{v}$ is the mean vehicle length based on classified traffic counts and manufacturer data, and $D_{S}$ is the stopping distance at a given speed (the sum of the thinking and braking distances, taken from the UK Highway Code, Department for Transport 2007).

Speeds were considered to account for variations in vehicle speed and speed limit. This was particularly important as the speed limit for the A85 site reduced from 60 mile/h $(97 \mathrm{~km} / \mathrm{h})$ to 50 mile $/ \mathrm{h}(80 \mathrm{~km} / \mathrm{h})$ during the study.

\section{$\mathrm{P}($ Fatality|Hit)}

$\mathrm{P}($ Fatality $\mid$ Hit $)$, or the human vulnerability (i.e. probability of a fatality given an impact between vehicle and debris), was defined as a quantitative expression of 


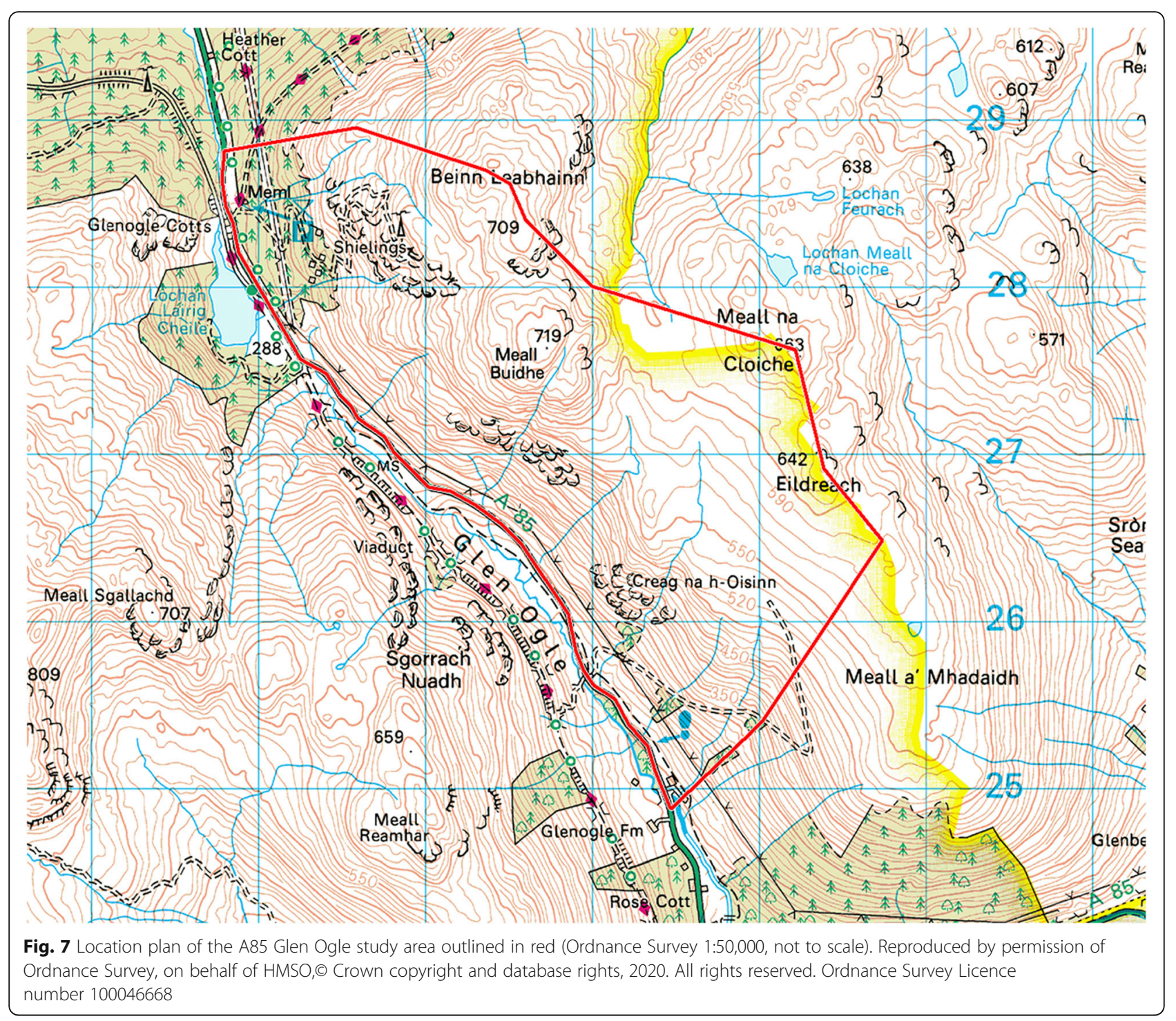

probability of death given an impact with a debris flow event reaching the road. It represents the likelihood of death within the danger zones of the debris flow hazard (i.e. 'Wrong Place' in Scenario A or B).

The major challenge with $\mathrm{P}($ Fatality $\mid$ Hit $)$ was the lack of information on impacts between debris and vehicles and the effects on vehicle occupants. A pragmatic, experiential-judgement approach was taken using the authors' experience of past debris flow and rock fall events, while colleagues from other institutions were canvassed informally for their experiences. Combined with compelling video evidence from internet sources a satisfactory scheme was developed for both scenarios, albeit that insufficient information was available to develop full fragility curves as has been done for the effects of debris flow on road infrastructure (Winter et al. 2014b). This scheme was evolved and modified in discussion with colleagues expert on the effects on vehicles involved in road traffic collisions with other vehicles and with stationary objects such as vehicle restraint systems.

\section{Results}

\section{Personal individual risk (PIR)}

Given the mobility of the elements at risk (vehicles and their occupants) it is clear that the concepts of 'Individual Risk' (ERM 1998) and of 'Location-specific individual risk' (Lee and Jones 2014), representing the risk for a theoretical individual exposed to a hazard for $100 \%$ of the time (i.e. $24 \mathrm{~h}$ per day, 365 days per year), are not relevant to this study. In contrast the 'Personal Individual Risk (PIR)' (ERM 1998) or 'Individual-specific individual risk (ISIR)' (Lee and Jones 2014), taking into account the temporal and spatial conditions of exposure of the elements at risk to the hazard (i.e. present at different locations during different periods), is appropriate. 


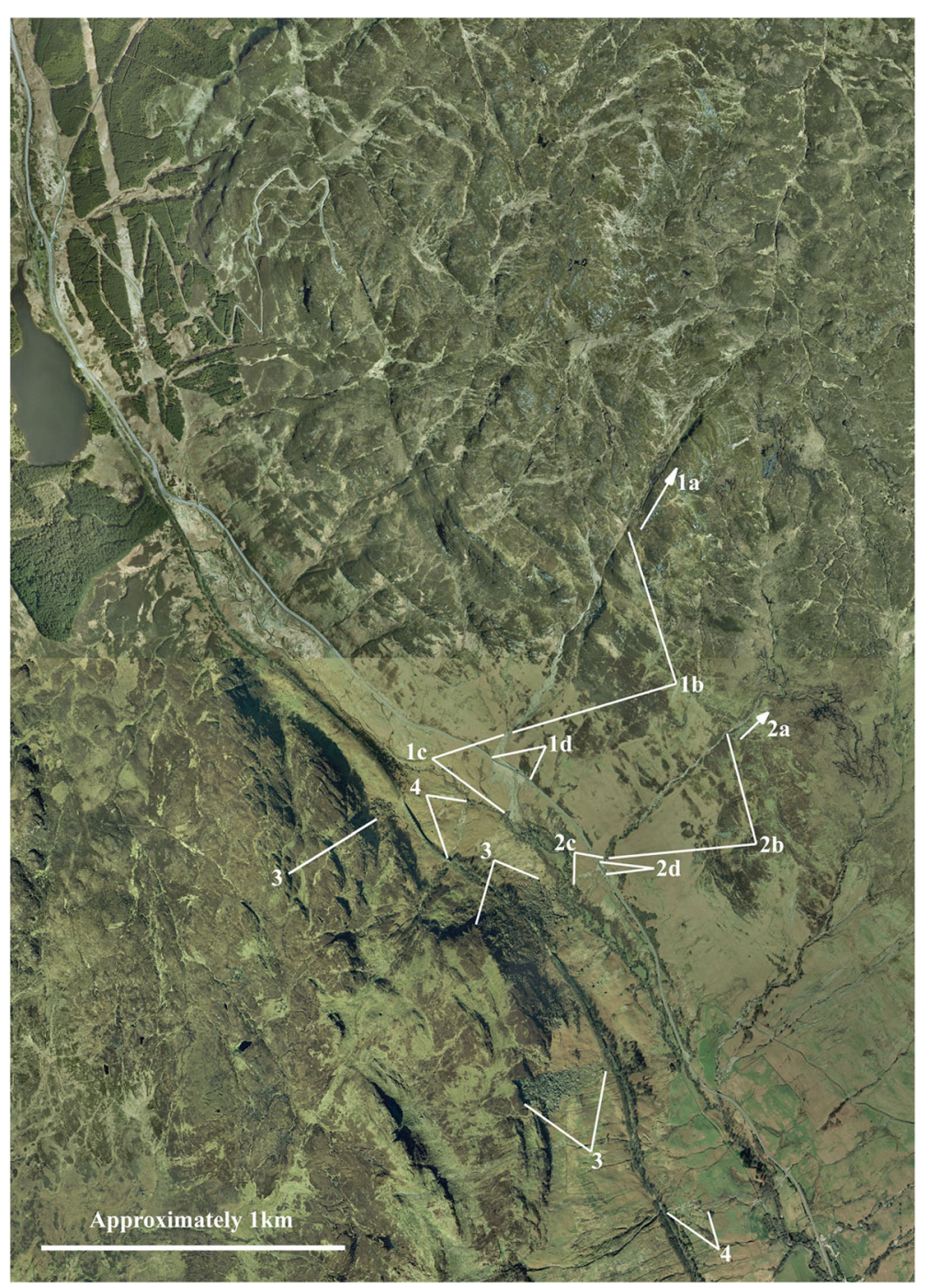

Fig. 8 Aerial photograph showing a large part of Glen Ogle. The image was made by stitching adjacent $1 \mathrm{~km}$ by $1 \mathrm{~km}$ tiles before cropping to give approximately $4 \mathrm{~km}$ (vertical) by $3 \mathrm{~km}$ (horizontal) coverage; north is to the top. (From Winter et al. 2009.). Key: 1. North debris flow: (a) potential source areas, (b) debris track, (c) runout/ debris fan and (d) subsequent carriageway repair. 2. South debris flow: (a) potential source areas, (b) debris track, (c) runout/ debris fan and (d) subsequent carriageway repair. 3. Historic rock falls. 4. Other debris flows assumed to have occurred in August 2004. Base aerial photography reproduced by permission of Ordnance Survey, on behalf of HMSO,® Crown copyright and database rights, 2020. All rights reserved. Ordnance Survey Licence number 100046668

As a road user on a single trip in the study area would be subjected to both risk scenarios $\mathrm{A}$ and $\mathrm{B}$, the total PIR is therefore the sum of the PIR under both scenarios. When calculated using the risk methodology set-out by Lee and Jones (2014) the PIR for a single trip by an individual through one or other of the two sites is as set out in Table 1.

Similarly the PIR for those most at risk can be calculated. In this study commuters, making daily return trips through a site on 5 days for 47 weeks a years, and that for logistics truck drivers, making two daily return trips through a site on 5 days per week for 47 weeks a year, were considered, noting that the National Speed Limit for goods vehicles over $7.5 \mathrm{t}$ (maximum laden weight) in Scotland is $40 \mathrm{mile} / \mathrm{h}$ (except for the A9 Perth to Inverness) (Table 2).

\section{Societal risk}

Societal risk is a measure of the overall risk associated with a situation or system (ERM 1998). It is the frequency and the number of people suffering a given level of harm from the realisation of specified hazards (IChemE 1992), and a measure of the likely impact of hazard scenarios, not just on a particular type of individual (as in the case of personal individual risk) but on all individuals who may be exposed to the risk. The societal 


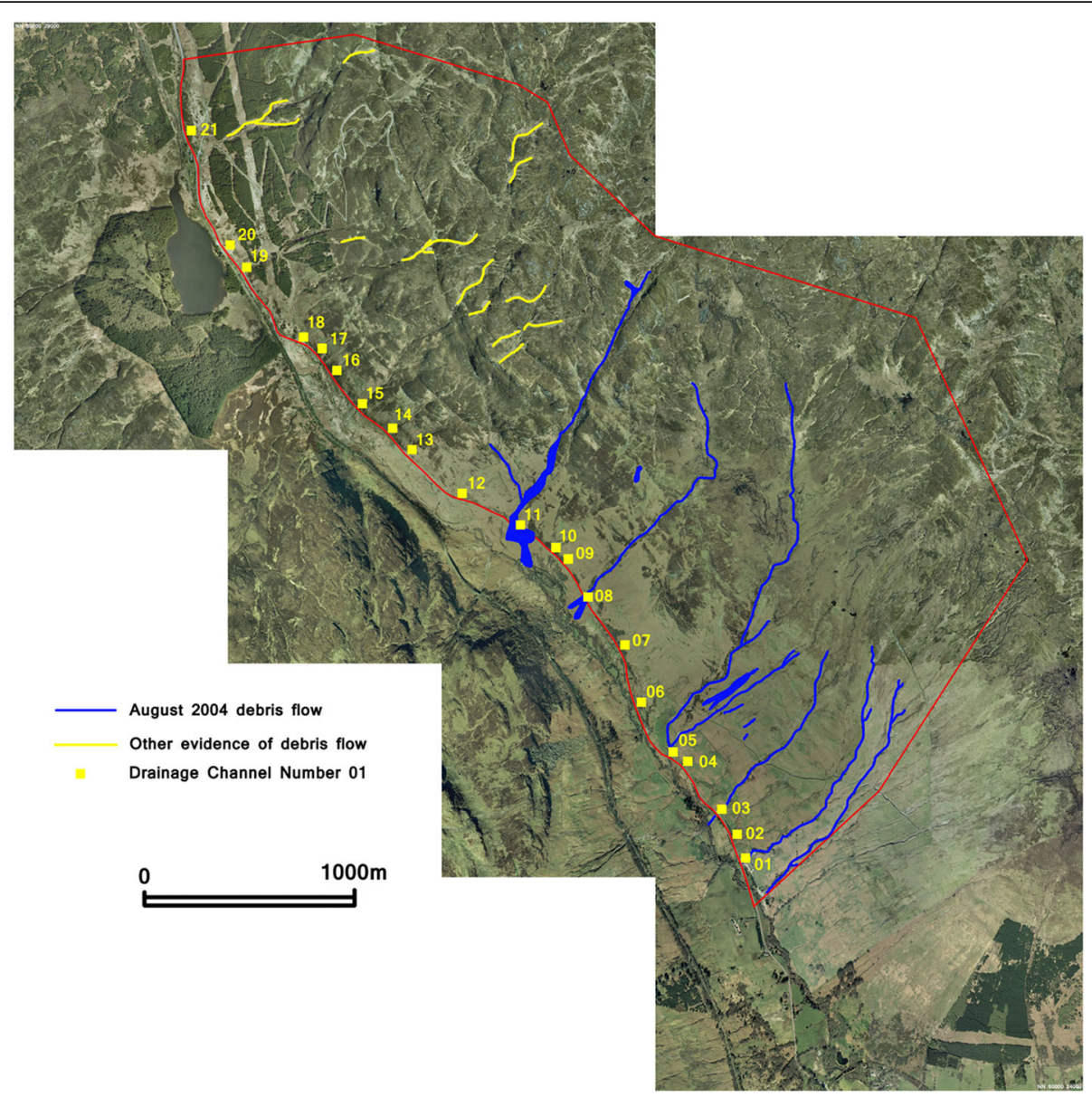

Fig. 9 Debris flow events with known locations and signs of instability determined from the aerial photography. Locations of the drainage channels at the A85 Glen Ogle as confirmed by field reconnaissance are also shown. Base aerial photography reproduced by permission of Ordnance Survey, on behalf of HMSO,® Crown copyright and database rights, 2020. All rights reserved. Ordnance Survey Licence number 100046668

risk of fatality to road users at the two sites was determined from the product of PIR and the exposed population, the latter being defined by the annual average daily traffic flow (Annual Average Daily Flow, two-way multiplied by 365.25 days/year).

This allows the Potential Loss of Life (PLL) to be calculated for each site; this is simply the annual probability of a single fatality from the population that uses the route.

A notional vehicle speed of 50 mile/h was assigned for the analysis of societal risk. This is considered to be typical of passenger vehicle speeds experienced at the sites (regardless of the speed limit) and is conservative for goods vehicles subject to a lower speed limit.

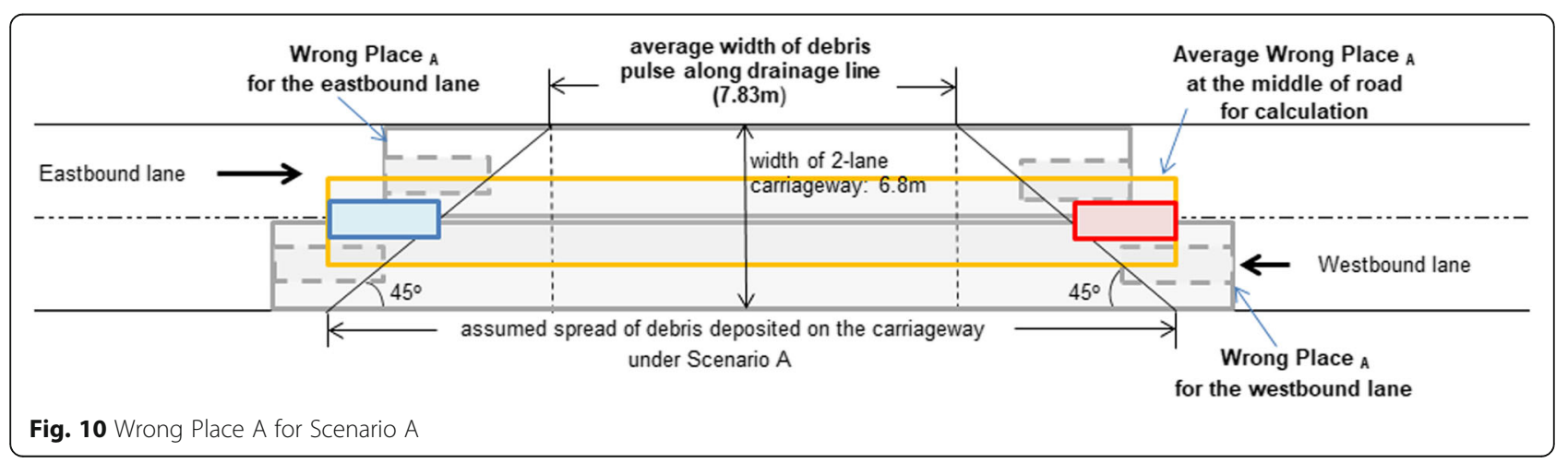




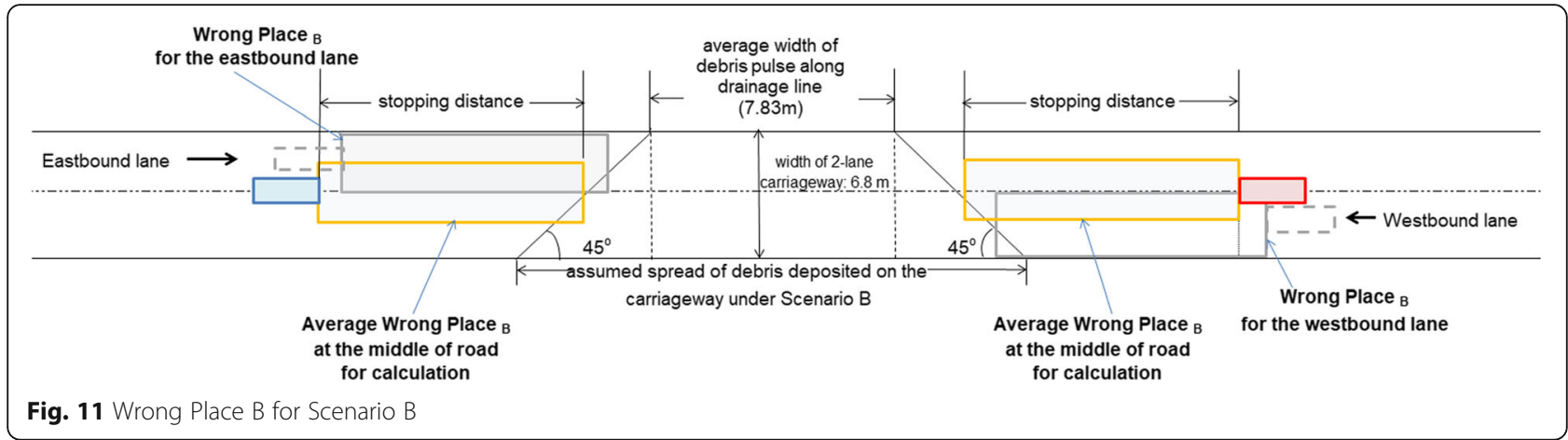

The PLL results show that the risk derived from Scenario A (vehicle being hit by a debris flow) is approximately one order of magnitude greater than that for Scenario B (vehicle hitting a debris from) (Table 3).

The PLL relates to the probability of a single fatality but there is a clear potential for multiple fatalities and here the method used follows that of Wong et al. (2004). Using the available data for traffic numbers, the associated breakdown of vehicle type and an estimate of the likely number of passengers in each vehicle type, six separate consequence situations were developed for scenarios involving 1, 2, 3, 4, 6 and 56 fatalities (number, $N$ ) and probabilities of each consequence occurring (frequency, $F$ ) were calculated.

The results of these calculations are presented in Figs. 12 and 13. The results for the A85 (Fig. 13) generally lie in the 'Broadly Acceptable' zone with $N=1$ and 2 lying in the 'As Low As Reasonably Practicable (ALARP)', $N=1$ and 2 for the A83 (Fig. 12) lie in the 'Unacceptable' zone with the remaining values being in the ALARP zone. Even though the UK is rightly considered as a low landslide risk environment (Gibson et al. 2012) this does illustrate the potential for significant, and broadly unacceptable, peaks in risk even within such an environment.

In this context it should be noted that no account of landslide risk reduction measures is made in Figs. 12 or 13. This is particularly important at the A83 site, at which a strategic approach has been taken to the reduction of landslide risk (Winter 2014) including educational leaflets, wig-wag warning signs (Fig. 14) (Winter

Table 1 Combined PIR for Scenarios A and B for a single trip per annum (PIR at the speed limit italicised)

\begin{tabular}{llll}
\hline & \multicolumn{3}{l}{ Initial Vehicle Speed: mile/h (km/h) } \\
\cline { 2 - 4 } & $40(64)$ & $50(80)$ & $60(97)$ \\
\hline A83 & $2.045 \mathrm{E}-09$ & $1.742 \mathrm{E}-09$ & $1.583 \mathrm{E}-09$ \\
A85 & $1.328 \mathrm{E}-10$ & $1.147 \mathrm{E}-10$ & $1.061 \mathrm{E}-10$ \\
\hline
\end{tabular}

et al. 2013b; Winter and Shearer 2017) and the provision of debris flow nets (Fig. 15).

At the time that the technical aspects of this work were concluded in October 2014 additional debris flow nets and catch pits were planned along with significant planting of the hillside to improve stability (Winter and Corby 2012). Additional nets and catch pits have since been installed and the planting programme is progressing through the planning stages. As part of this work the effect on the risk of fatalities of the landslide risk reduction measures that were in place as of October 2014 was assessed.

This was achieved by the use of an event tree diagram and carefully considering (and testing) the contribution to hazard reduction and that each element of the strategic programme made and then calculating the revised risk levels in terms of $F-N$ (Fig. 16). This process was made possible from the detailed evaluation of the wig-wag signs (Winter et al. 2013b) and events that had occurred and tested the efficacy of the debris flow nets. As can be seen in Fig. 16), taking account of the landslide risk reduction measures brings the risk back to the ALARP zone for all values of $N$.

\section{Discussion}

\section{Individual risk}

In a comparison of risk regulation in the UK and the Netherlands, Ale (2005) noted that following the Sizewell B Enquiry the Health \& Safety Executive (HSE) (Anon. 1992) described a tolerable risk level as one that is allowed to continue to exist somewhere in society. The highest tolerated risk at that time in the UK was that to miners and the individual risk to those workers was estimated to be of the order of 1E-03 $\left(10^{-3}\right)$ per year. From that it was derived that members of the general public could be exposed to an individual risk of 1E-04 $\left(10^{-4}\right)$ per year in the wider interests of society. 
Table 2 Combined PIR for Scenarios A and B for individuals most at risk: commuters and logistics truck drivers (PIR at the speed limit italicised)

\begin{tabular}{lll}
\hline Individuals most at Risk & Commuters & $\begin{array}{l}\text { Logistics Truck } \\
\text { Drivers }\end{array}$ \\
$\begin{array}{l}\text { Initial Vehicle Speed: } \\
\text { mile/h (km/h) }\end{array}$ & $50(80) / 60(97)$ & $40(64)$ \\
\hline A83 & $7.440 E-07$ & $1.922 E-06$ \\
A85 & $5.391 E-08 / 4.987 \mathrm{E}-08$ & $1.248 E-07$ \\
\hline
\end{tabular}

This compares to the computed Personal Individual Risk (PIR) of fatality for a single trip (per year) which is speed dependent (Table 1) and varies from

- 2.045E-09 (40 mile/h), 1.742E-09 (50 mile/h) to 1.583E-09 (60 mile/h) at the A83 Rest and be Thankful, and

- $1.328 \mathrm{E}-10$ (40 mile/h), 1.147E-10 (50 mile/h) to 1.061E-10 (60 mile/h) at A85 Glen Ogle.

Those who make multiple trips are exposed to a greater level of risk.

Estimates of the annual probability of fatality for those most at risk have been made for commuters and logistics truck drivers and the highest probability is around 2E-06 fatalities per year or once every 520,000 years, while the lowest probability corresponds to around 5E08 or around 1 in 20 million years (Table 2).

The values of PIR are considerably lower than those that Lee and Jones (2014) suggest that the UK Health and Safety Executive currently use to define the upper $\left(1 \mathrm{E}-04\right.$ or $\left.10^{-04}\right)$ and lower $\left(1 \mathrm{E}-06\right.$ or $\left.10^{-06}\right)$ bounds of As Low As Reasonably Practicable for individual risk and may be described as Broadly Acceptable or tolerable; the exception is the risk for the logistics truck driver which falls just within the ALARP zone. These risks are noticeably lower than those described by Ale (2005).

The results for the two parts of this risk assessment (debris flow hitting vehicle and vehicle hitting debris flow) show, unsurprisingly and as noted above, that the resulting risk is vehicle speed dependent, albeit to a relatively small degree. It is important to apply these results in context. The larger overall risk of a debris flow hitting a vehicle (Scenario A) has a decreasing risk for higher

Table 3 Societal risk in terms of the PLL (50 mile/h vehicle speed)

\begin{tabular}{llll}
\hline & \multicolumn{3}{l}{ Societal Risk: Potential Loss of Life, PLL } \\
\cline { 2 - 4 } & $\begin{array}{l}\text { Scenario A } \\
\text { (debris flow hits vehicle) }\end{array}$ & $\begin{array}{l}\text { Scenario B } \\
\text { (vehicle hits debris flow) }\end{array}$ & $\begin{array}{l}\text { Scenario } \\
\text { A + B }\end{array}$ \\
\hline A83 & $3.612 \mathrm{E}-03$ & $4.716 \mathrm{E}-04$ & $4.083 \mathrm{E}-03$ \\
A85 & 2.249E-04 & $3.671 \mathrm{E}-05$ & $2.616 \mathrm{E}-04$ \\
\hline
\end{tabular}

speeds, while the overall lower risk of a vehicle hitting a debris flow (Scenario B) has an increased risk with increasing speed (Fig. 17).

Overall the risk of a fatality (Scenario A plus B) from a debris flow shows a small decrease with vehicle speed. It is important that increased speed is not seen, in any way, as an effective remedial measure, or tactic, for drivers to reduce the overall risk that they face on the road. It is important to recognise that increased speed also increases the (considerably higher) risk of a road traffic accident and reduces the control that a driver may have over the vehicle in the event of encountering a debris flow. Recommendations to drivers should focus on the balance of speed to driving conditions as such recommendations would in any other scenario.

\section{Societal risk}

The societal risk from debris flow at the A85 Glen Ogle is dealt with in terms of the classic, and widely used, $F$ $N$ diagram. There are two approaches to generating the data to be plotted on this diagram as described by Wong et al. (2004) and by Lee and Jones (2014); neither is considered to be more correct than the other. In this study a speed of $50 \mathrm{mile} / \mathrm{h}$ has been taken as an estimate of the average speed of traffic at the two sites. The approach of Lee and Jones (2014), while not presented here, produces values of $N$ that include some that are less than unity, the lowest value on the $\mathrm{x}$-axis, which do not plot on the $F-N$ diagram that has its lower bound value at unity (see Wong and Winter 2018; Winter 2018). The approach of Wong et al. (2004) produces results that are more suited to being plotted on the $F-N$ diagram and a clearer picture emerges (Figs. 12 and 13).

Figure 12 shows that prior to the application of mitigation measures the risk levels for one and two fatalities $(N=1$ and 2$)$ plot just into the Unacceptable zone, while the risks for higher numbers of fatalities plot in the ALARP zone. The application of reductions to the risk levels in response to the mitigation measure implemented at the A83 Rest and be Thankful (Fig. 16) brings the value for $N=2$ into the ALARP zone and that for $N=1$ only fractionally into the Unacceptable zone. The initial intrusion of the data into the Unacceptable zone is considered to be within the limits of error of the study and thus the overall risk levels can be considered to be within the ALARP zone after mitigation. This indicates the value and effectiveness of the mitigation measures implemented.

For the A85 Glen Ogle site the diagram (Fig. 13) shows that the risk levels plot broadly in the ALARP zone for lower numbers of fatalities and in the Broadly Acceptable risk zone for higher numbers of fatalities. 


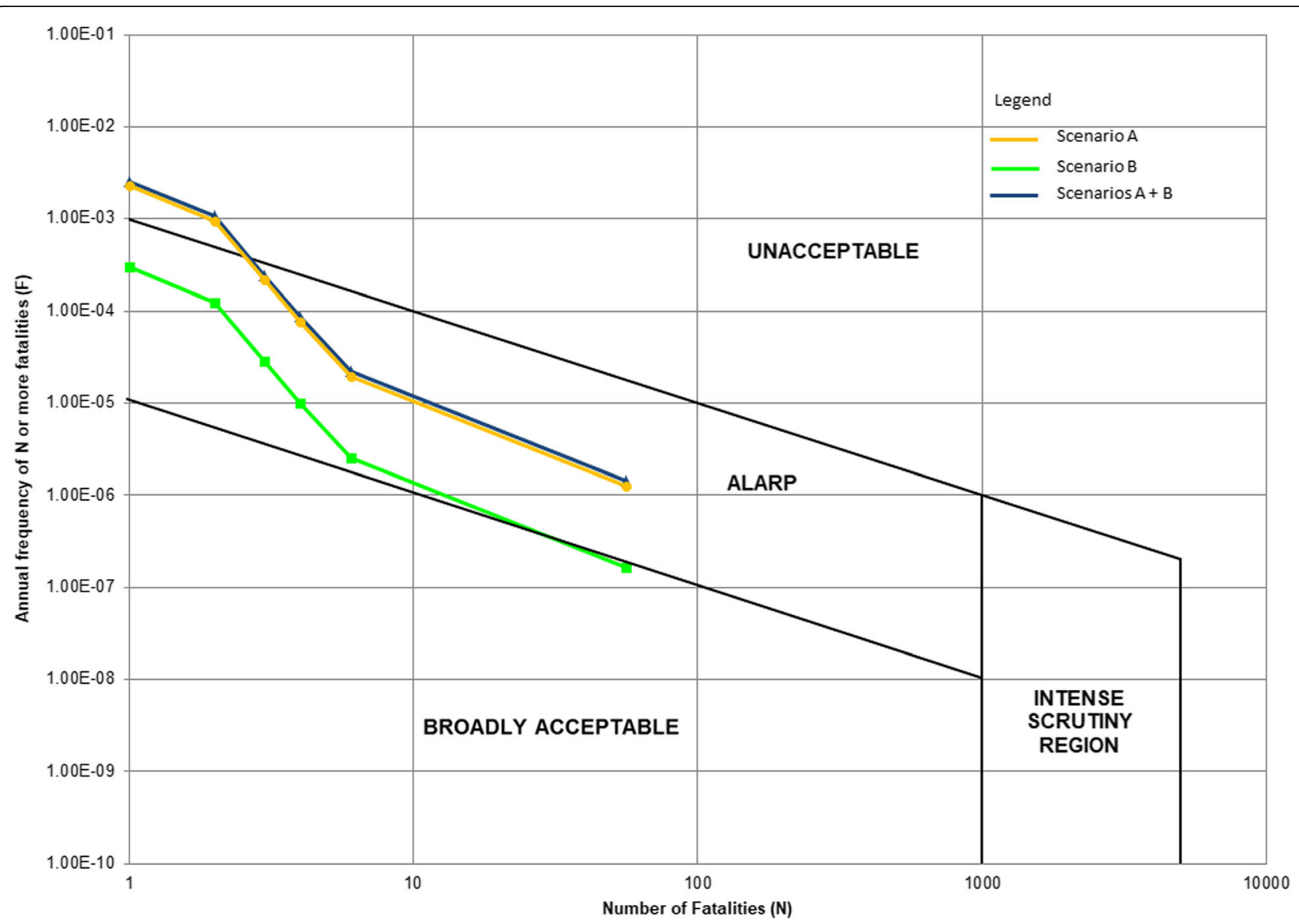

Fig. 12 F-N curves based on the Wong et al. (2004) approach for the A83, before mitigation measures (compare to Fig. 16)

The Lee and Jones (2014) methodology is particularly helpful in that it allows the ready calculation of a figure for the Potential Loss of Life (PLL). This is the annual probability of a fatality being caused by debris flow. At the A83 Rest and be Thankful, for an average traffic speed of $50 \mathrm{mile} / \mathrm{h}$, this is $4.083 \mathrm{E}-03$, corresponding to one fatality every 245 years or approximately four fatalities per millennium. At the A85 Glen Ogle and, for the same average traffic speed, the PLL is 2.616E-04, which corresponds to one fatality every 3822 years (Table 3 ).

\section{Climate change}

Climate change will have an impact on the frequency and magnitude of such events and the potential impact of increased rainfall on landslide and flood events has been widely discussed (e.g. Barnett et al., 2006a, b; Duan et al. 2015, 2016, 2019).

In broad terms the available climate change forecasts suggest that in the winter months when rainfall is expected to increase, landslide hazard frequency and/or magnitude may increase in Scotland in the future, whereas in the summer months the frequency may decrease, but with a possibility of increasing magnitude (Winter and Shearer 2014a, 2014b).

Increased hazard frequency, or $\mathrm{P}($ Event $)$, is relatively straight forward to deal with and Eq. (2) suggests that doubling, for example, the frequency of event occurrence would double the risk. This would increase the risk to logistics truck drivers using the A83 from 1.922E-06 to 3.844E06 (at the speed limit for heavy goods vehicles of $40 \mathrm{mile} / \mathrm{h}$ and from 1.248E-07 to 2.496E-07 for those using the A85, still well within the highest tolerated individual risk to workers of $1 \mathrm{E}-03\left(10^{-3}\right)$ per year, as reported by Ale (2005).

Increases in hazard magnitude would have an influence on $\mathrm{P}($ Damage $\mid$ Hit $)$, while $\mathrm{P}($ Hit $\mid$ Event $)$ seems unlikely to change to such a significant degree. This increase in $\mathrm{P}($ Damage|Hit $)$ seem likely to be greater in Scenario A than in Scenario B. Taking a lead from fragility curves for road infrastructure (Winter et al. 2014b), it seems reasonable to suggest that a doubling in the magnitude may lead to a doubling of the risk and a broadly similar outcome as for a doubling of the event frequency. While a doubling of the event frequency would still leave the societal risk at the A85 within the ALARP 


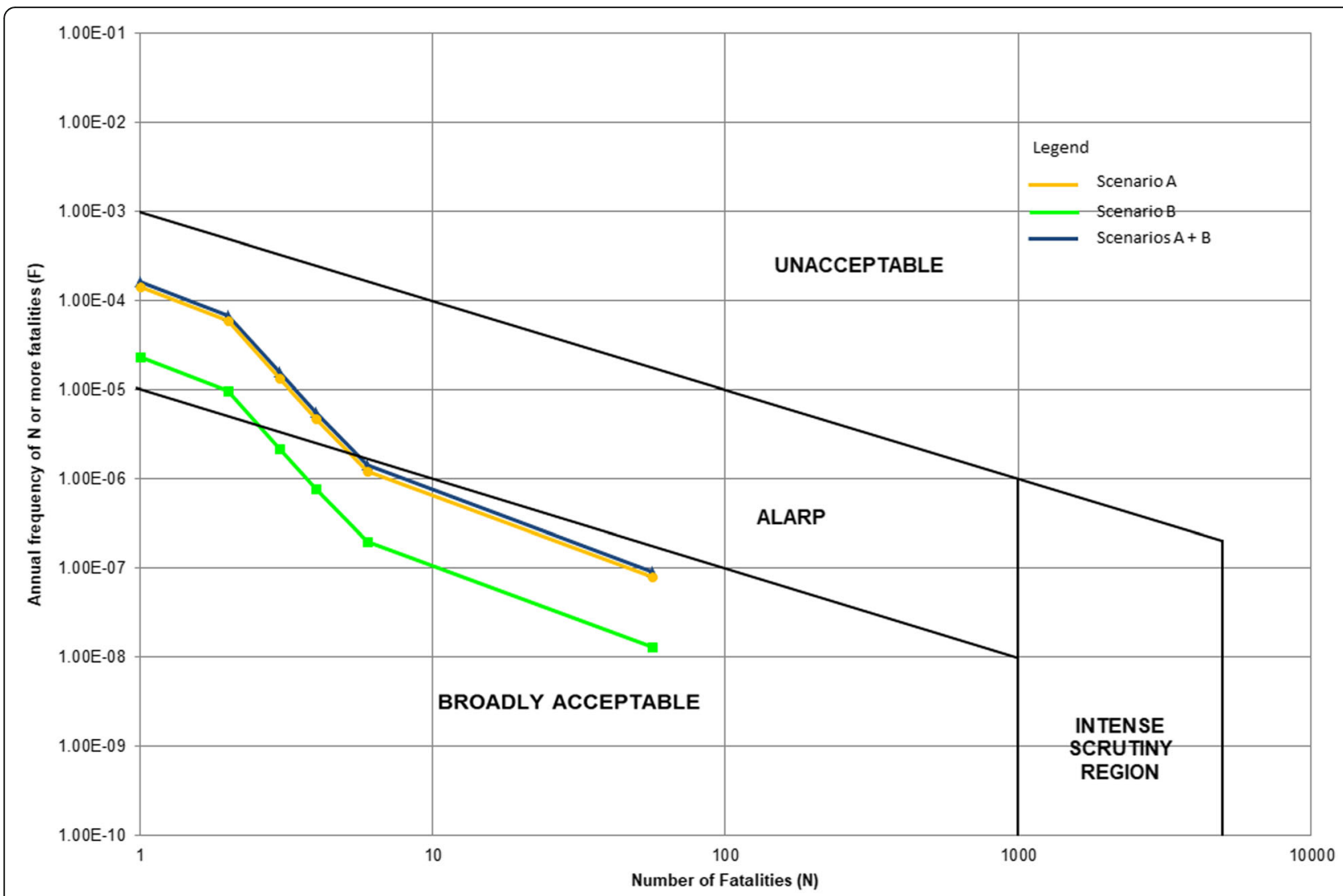

Fig. 13 F-N curves based on the Wong et al. (2004) approach for the A85

zone for smaller numbers of fatalities and in the Broadly Acceptable zone for higher numbers of fatalities, the picture at the A83 is rather different and the societal risk would return to the lower reaches of the Unacceptable zone on the $F-N$ diagram for low numbers of fatalities $(N=1$ or 2$)$.

Of course, an assumption of the doubling of either frequency or magnitude is rather speculative and it must be remembered that frequency and magnitude are not completely decoupled; an increase in magnitude may leave less loose previously mobilised material to be entrained and may lead to a decrease in the frequency, similarly an increase in the frequency may well mean that the channels are relatively clear of such material and it may be less likely that a larger magnitude event will develop. In addition, such increases must be offset against the substantial additional landslide risk reduction measures that have
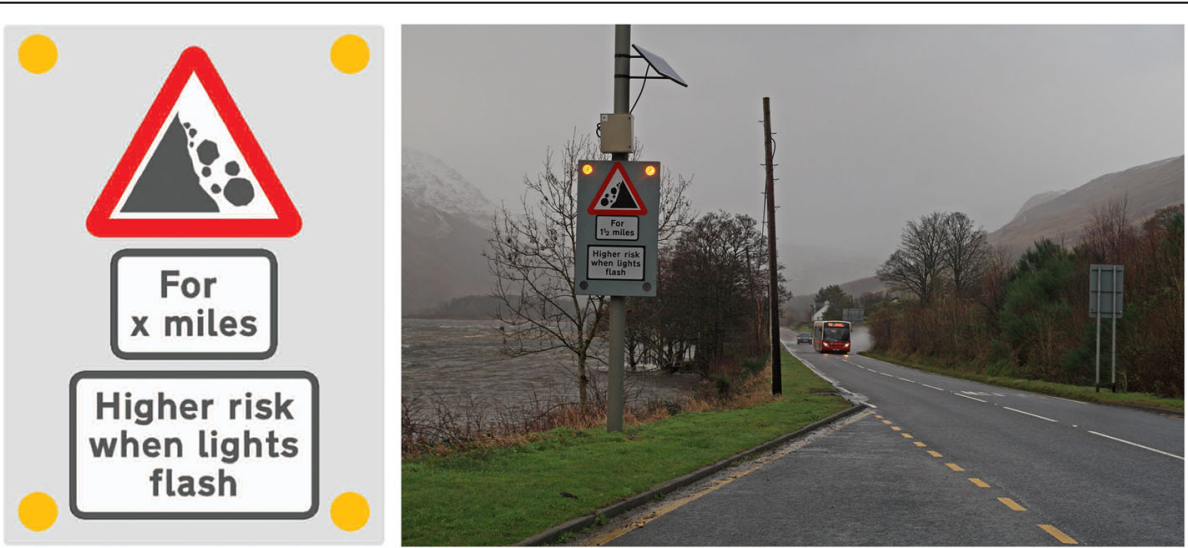

Fig. 14 Wig-wag warning sign in operation at the A83 Rest and be Thankful 


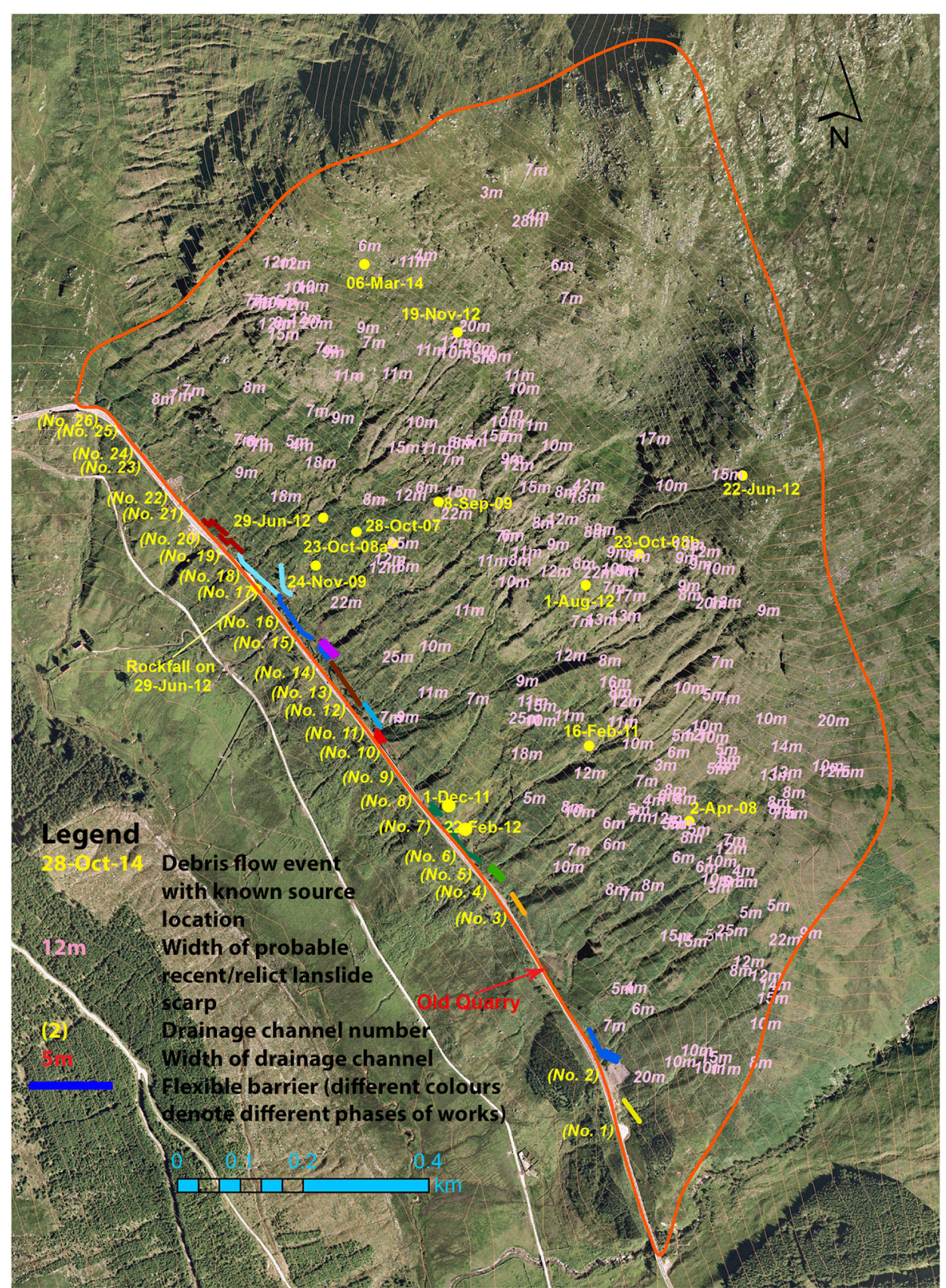

Fig. 15 Locations of the flexible barriers and catch pit at the A83 Rest and be Thankful. Base aerial photography reproduced by permission of Ordnance Survey, on behalf of HMSO, $\odot$ Crown copyright and database rights, 2020. All rights reserved. Ordnance Survey Licence number 100046668

been implemented at the Rest and be Thankful since October 2014 when the data for this study was collected.

It is, of course, not sufficient to consider only the effect of climate change on the hazard and the effects of demographic change, including travel patterns, also must be considered and may be either coupled and/or decoupled to the effects of climate change. Typically, such changes are found to be at least as important as the changes to the hazard (Winter and Shearer 2013; Milne et al., 2016; Winter et al. 2017).

\section{Landslide frequency and inventory}

Perhaps the most challenging aspect of this work was the evaluation of landslide frequency. This was a direct result of the relative paucity of data relating to past landslides, even for the Rest and be Thankful site the recorded record covers a period of less than two decades while at Glen Ogle the relative infrequency of events provided the challenge.

Wong and Winter (2018) recommended that a more complete and systematic database of the landslide history of the A83 Rest and be Thankful and other sites 

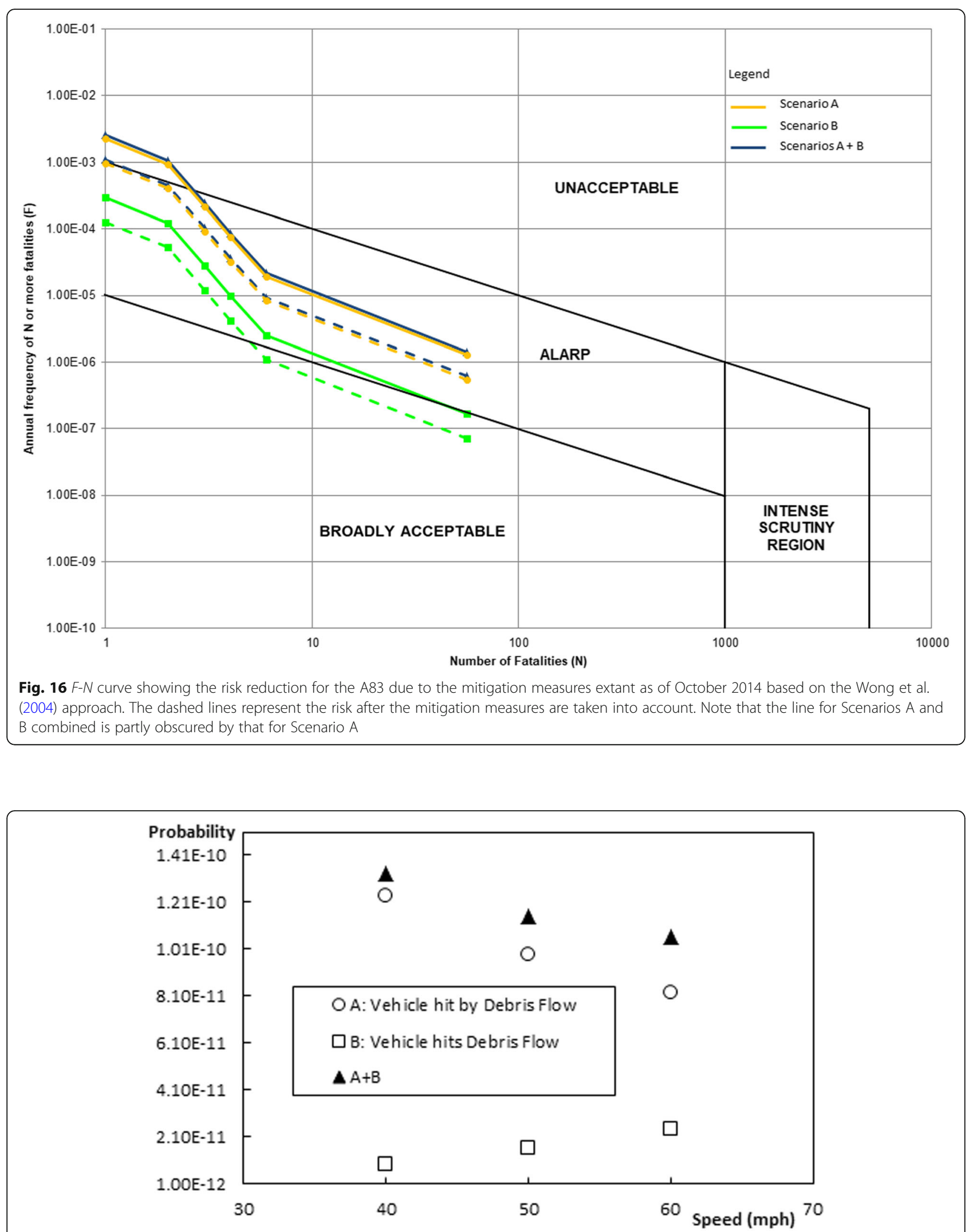

Fig. 17 The variation of PIR for the two risk scenarios and total risk with speed at the A85 Glen Ogle. A similar pattern is evident for the A83 site albeit with different numbers 
around Scotland site should be implemented and this is being taken forward for the strategic road network.

\section{Limitations}

In addition to the limitations set-out in the foregoing sections, including but not limited to the landslide inventory, it is important to note that the QRA technique is neither a neutral, nor is it an entirely objective, process such that the results could be value-laden and biased (Lee and Jones 2014). Suzanne Lacasse describes QRA as "... the systematic application of engineering judgement" in her, as yet unpublished, 2015 Rankine Lecture. The QRA methodology was developed based on a review of the application of QRA in landslide studies in different parts of the world and the site-specific information available. Particular care was taken to avoid systematic unidirectional bias and to balance the application of conservatism in areas where there were significant uncertainties with a less conservative approach in other area. The uncertainties were tested using a process of challenge and counter-challenge by the members of the team and with internal reviewers in order to ensure that a balance was applied to the different factors assessed in the risk analysis, including the testing of alternative judgement options to those proposed. Such tests were also conducted with colleagues with relevant expertise including inter alia vehicle impacts and those with extensive knowledge and experience of the road network, and the routes and sections under consideration.

\section{Conclusions}

Landslides and debris flow hazards can pose significant risk to the socio-economic activities of communities and the risks include those related to the provision of opportunities for education, employment and healthcare as well as presenting obstacles to the movement of goods to and from an area for commerce and of people for tourist and leisure activities.

In this paper QRA for the effect of debris flow on road users (potential fatalities) are reported for a high frequency-low magnitude site and a low frequency-high magnitude site.

The PIR for a single trip through the sites ranges between 1.147E-10 for the low frequency-high magnitude site and 1.583E-09 for the high frequency-low magnitude site. These figures increase to $1.248 \mathrm{E}-07$ and 1.922E-06, respectively, when more frequent travellers are considered. The PLL for the two sites ranges between 2.616E-04 for the low frequency-high magnitude site and 4.083E-03 for the high frequencylow magnitude site.

The F-N diagrams illustrate the Broadly Acceptable level of risk at the low frequency-high magnitude site and the partially Unacceptable level of risk at the high frequency-low magnitude site. The risk at the high frequency-low magnitude site is reduced to ALARP levels when management and mitigation measures extant as of October 2014 are considered.

The QRA proves an effective technique for understanding, comparing and articulating the differences in levels of risk and the temporal changes in risk at a given site as a result of landslide risk reduction activities.

The two sites considered in this study contain only moving vehicles and their occupants; there is no formal provision for vehicles to stop or park in these sections. This means that the only two possible scenarios for the interaction of vehicles and debris flow are for a (moving) vehicle being hit by a debris flow that reaches the road and that of a vehicle hitting a debris flow that has already reached the road. At other sites where formal stopping or parking opportunities exist, a third scenario is possible whereby a debris flow could hit a stationary vehicle. This scenario has the potential to be associated with high levels of risk and the study of such sites and the development a methodology to assess the quatitive risk to the occupants of such vehicles would be a logical extension of the work presented here.

\section{Abbreviations}

ALARP: As Low As Reasonably Practicable; AOD: Above Ordnance Datum; FN: Frequency-Number; GIS: Geographical Information Systems; PIR: Personal Individual Risk; PLL: Personal Loss of Life; QRA: Quantitative risk assessment

\section{Acknowledgements \\ This work was conducted during the second author's secondment to TRL in 2014 from the Geotechnical Engineering Office (GEO) of the HKSARG's Civil Engineering and Development Department (CEDD). The authors thank the GEO, CEDD and HKSARG for facilitating this secondment, in particular H. N. Wong, P. L. R. Pang, K. K. S. Ho, W. K. Pun and S. K. C. Ng. This paper is published with the permission of the Head of the GEO and the Director of Civil Engineering and Development, HKSARG. \\ Gavin Williams and Iwan Parry (TRL) are thanked for useful discussions and advice in relation to the likely results of the impact of vehicles with debris flow and of the impact of debris flow with vehicles. \\ The funding of Transport Scotland and the Scottish Road Research Board for this work is gratefully acknowledged. \\ This paper is published with the permission of Transport Scotland and TRL Limited.}

\section{Authors' contributions}

MGW designed the study and secured the funding. JCFW developed the methodology and applied it to the A83 site in collaboration with and under the supervision of MGW. MGW applied the methodology to the A85 site. MGW wrote the paper and JCFW reviewed the paper. Internal TRL and GEO review processes were also followed. All authors read and approved the final manuscript.

\section{Funding}

The funding of Transport Scotland and the Scottish Road Research Board for this work is gratefully acknowledged.

Availability of data and materials

Relevant data is presented in the paper.

Ethics approval and consent to participate

Not applicable. 


\section{Consent for publication}

This paper is published with the permission of Transport Scotland and TRL Limited.

\section{Competing interests}

The authors declare that they have no competing interest.

\section{Author details}

${ }^{1}$ Formerly Transport Research Laboratory (TRL), Edinburgh now Winter Associates, Kirknewton, Midlothian, UK. ${ }^{2}$ University of Portsmouth, Portsmouth, UK. ${ }^{3}$ Geotechnical Engineering Office, Civil Engineering \& Development Department, Kowloon, Hong Kong SAR.

Received: 15 May 2019 Accepted: 29 December 2019 Published online: 08 January 2020

\section{References}

Ale BJM (2005) Tolerable or acceptable: a comparison of risk regulation in the United Kingdom and the Netherlands. Risk Anal 25(2):231-241

Anon. (1992) The tolerability of risk from nuclear power stations (revised) HMSO, London

Anon. 2013. A83 trunk road route study: part a - A83 rest and be thankful. Final report. Report prepared by Jacobs for transport Scotland, 212p. (Accessed 1 Feb 2014: http://www.transportscotland.gov.uk/road/maintenance/landslides)

Barnett C, Perry M, Hossell J, Hughes G, Procter C (2006a) A handbook of climate trends across Scotland; presenting changes in the climate across Scotland over the last century. 58p. SNIFFER Project CC03. Scotland and Northern Ireland forum for environmental research, Edinburgh

Barnett C, Perry M, Hossell J, Hughes G, Procter C (2006b) Patterns of climate change across Scotland: technical report, 102p. SNIFFER project CC03. Scotland and Northern Ireland Forum for Environmental Research, Edinburgh

Corominas J, van Westen C, Frattini P, Cascini L, Malet J-P, Fotopoulou S, Catani F, Van Den Eeckhaut M, Mavrouli O, Agliardi F, Pitilakis K, Winter MG, Pastor M, Ferlisi S, Tofani V, Hervás J, Smith JT (2014) Recommendations for the quantitative analysis of landslide risk. Bull Eng Geol Environ 73(2):209-263

Department for Transport. 2007. The Highway Code. (Accessed Oct 2014: https:// www.gov.uk/highway-code)

Duan W, Hanasaki N, Shiogama H, Chen Y, Zou S, Nover D, Zhou B, Wang Y (2019) Evaluation and future projection of Chinese precipitation extremes using large ensemble high-resolution climate simulations. J Clim 32(8):2169-2183

Duan W, He B, Nover D, Fan J, Yang G, Chen W, Meng H, Liu C (2016) Floods and associated socioeconomic damages in China over the last century. Nat Hazards 82(1):401-413

Duan W, He B, Takara K, Luo P, Hu M, Alias NE, Nover D (2015) Changes of precipitation amounts and extremes over Japan between 1901 and 2012 and their connection to climate indices. Clim Dyn 45:2273-2292

ERM (1998) Landslides and boulder falls from natural terrain: interim risk guidelines. GEO Report No. 75. Geotechnical Engineering Office, Hong Kong, p 183

Gibson AD, Culshaw MG, Dashwood C, Pennington CVL (2012) Landslide management in the UK-the problem of managing hazards in a 'low-risk' environment. Landslides 10(5):599-610

HSE (2001) Reducing risk, protecting people. HMSO, Norwich

IChemE (1992) Nomenclature for hazard and risk assessment in the process industries. Institution of Chemical Engineers, Rugby

Lee EM, Jones DKC (2014) Landslide risk assessment, 2nd edn. ICE Publishing, London, $509 p$

McMillan FN, Holt CA (2019) BEAR Scotland NW trunk road maintenance: efficient management of geotechnical emergencies. Quart J Eng Geo Hydro 52:286-294

Milne FD (2008) Topographic and material controls on the Scottish debris flow geohazard. Unpublished PhD Thesis. University of Dundee, Dundee

Milne FD, Browne MJ, Werritty A (2010) A hazardous channelized debris flow in Glen ogle, Stirlingshire. Scott J Geol 46:169-180

Milne FD, Werritty A, Davis MCR, Browne MJ (2009) A recent debris flow event and implications for hazard management. Q J Eng Geol Hydrogeol 42:51-60

Milne FD, Winter MG, Reeves SJ, Knappett JK, Dawson S, Dawson A, Peeling D, Peeling J, Brown MJ (2016) Assessing the risks to infrastructure from coastal storms in a changing climate. In: Published project report PPR 800. Transport Research Laboratory, Wokingham

Redshaw, P., Dijkstra, T., Free, M., Jordan, C., Morley, A. and Fraser, S. 2017. Landslide risk assessment for the built environment in sub-saharan Africa. Advancing
Culture of Living with Landslides: Volume 5, Landslides in Different Environments Mikoš, M., Vilímek, V., Yin, Y. Sassa, K.), 5-12, Springer, Switzerland Wilson CR (2006) Historical landslide activity at Glen ogle, Scotland, using aerial photography and airborne hyperspectral data from the compact airborne spectrographic imager (CASI). Unpublished MSc Thesis. University of Dundee, Dundee

Winter MG (2014) A strategic approach to landslide risk reduction. Int I Landslide Environ 2(1):14-23

Winter MG (2018) The quantitative assessment of debris flow risk to road users on the Scottish trunk road network: A85 Glen ogle. Published project report PPR 799. Transport Research Laboratory, Wokingham

Winter MG (2019) Landslide hazards and risks to road users, road infrastructure and socio-economic activity. Geotechnical Engineering, Foundation of the Future. Icelandic Geotechnical Society, Reykjavik, pp 196-228

Winter, M.G. 2020. Debris flows. In: Geological Hazards in the UK: their Occurrence, Monitoring and Mitigation: Giles, D. P. and Griffiths, J. S. Engineering Geology Special Publication 29. London: Geological Society. (In Press)

Winter MG, Corby A (2012) A83 rest and be thankful: ecological and related landslide mitigation options. Published project report PPR 636. Transport Research Laboratory, Wokingham

Winter MG, Harrison M, Macgregor F, Shackman L (2013a) Landslide hazard assessment and ranking on the Scottish road network. Proc Inst Civil Eng (Geotechnical Engineering) 166(GE6):522-539

Winter MG, Heald A, Parsons J, Shackman L, Macgregor F (2006) Scottish debris flow events of august 2004. Q J Eng Geol Hydrogeol 39:73-78

Winter MG, Kinnear N, Shearer B, Lloyd L, Helman S (2013b) A technical and perceptual evaluation of wig-wag signs at the A83 rest and be thankful. Published project report PPR 664. Transport Research Laboratory, Wokingham

Winter MG, Macgregor F, Shackman L (eds) (2005) Scottish Road Network Landslides Study, 119p. The Scottish Executive, Edinburgh

Winter MG, Macgregor F, Shackman L (eds) (2009) Scottish road network landslides study: implementation, 278p. Transport Scotland, Edinburgh

Winter MG, Ognissanto F, Martin LA (2019) Rainfall thresholds for landslides: deterministic and probabilistic approaches. Published project report PPR 901. Transport Research Laboratory, Wokingham

Winter, M.G., Palmer, D., Sharpe, J., Shearer, B., Harmer, C., Peeling, D. and Bradbury, T. 2014a. Economic impact assessment of landslide events. Landslide Science for a Safer Geoenvironment, Volume 1: The International Programme on Landslides (IPL): Sassa, K., Canuti, P., Yin, Y.), 217-222. New York: Springer

Winter MG, Shearer B (2013) Climate change and landslide hazard and risk - a Scottish perspective. Published project report PPR 650. Transport Research Laboratory, Wokingham

Winter, M. G. and Shearer, B. 2014a. Landslide hazard and risk in a changing climate. Landslide Science for a Safer Geoenvironment, Volume 1: The International Programme on Landslides (IPL) : Sassa, K., Canuti, P., Yin, Y, 281286. New York: Springer

Winter, M. G. Shearer, B. 2014b. Climate change and landslide hazard and risk in Scotland. Engineering Geology for Society and Territory - Volume 1: Climate Change and Engineering Geology: Lollino, G., Manconio, A.r, Clague, J., Shan, W. and Chiarle, M, 411-414. Heidelberg: Springer

Winter MG, Shearer B (2017) An extended and updated technical evaluation of wig-wag signs at the A83 rest and be thankful. Published project report PPR 743. Transport Research Laboratory, Wokingham

Winter MG, Shearer B, Palmer D, Peeling D, Peeling J, Harmer C, Sharpe J (2018) Assessment of the economic impacts of landslides and other climate-driven events. Published project report PPR 878. Transport Research Laboratory, Wokingham

Winter MG, Smith JT, Fotopoulou S, Pitilakis K, Mavrouli O, Corominas J, Argyroudis S (2014b) An expert judgement approach to determining the physical vulnerability of roads to debris flow. Bull Eng Geol Environ 73:291-305

Wong HN, Ko FWY, Hui THH (2004) Assessment of landslide risk of natural hillsides in Hong Kong. GEO Report No. 191. Geotechnical engineering office, Hong Kong, p 120

Wong JCF, Winter MG (2018) The quantitative assessment of debris flow risk to road users on the Scottish trunk road network: A85 Glen ogle. Published project report PPR 798. Transport Research Laboratory, Wokingham

\section{Publisher's Note}

Springer Nature remains neutral with regard to jurisdictional claims in published maps and institutional affiliations. 